\title{
Editorial
}

\section{LIAC Meeting on Vascular Research 2013}

\author{
Marilena Formato, ${ }^{1}$ Vincenzo La Carrubba, ${ }^{2}$ Antonio J. Lepedda, ${ }^{1}$ \\ Philippe Charpiot, ${ }^{3}$ and José Carlos Rodriguez-Cabello ${ }^{4}$ \\ ${ }^{1}$ Dipartimento di Scienze Biomediche, Università degli Studi di Sassari, 07100 Sassari, Italy \\ ${ }^{2}$ Dipartimento di Ingegneria Civile, Ambientale, Aerospaziale, dei Materiali, Università degli Studi di Palermo, \\ 90128 Palermo, Italy \\ ${ }^{3}$ Département de Biologie Pharmaceutique-Laboratoire de Biochimie Fondamentale, Moléculaire et Clinique, \\ Université d'Aix-Marseille, INSERM UMR S1076, 13385 Marseille, France \\ ${ }^{4}$ G.I.R. BIOFORGE (Group for Advanced Materials and Nanobiotechnology), Universidad de Valladolid, \\ CIBER-BBN, 47011 Valladolid, Spain
}

Correspondence should be addressed to Marilena Formato; formato@uniss.it

Received 26 March 2015; Accepted 26 March 2015

Copyright (C) 2015 Marilena Formato et al. This is an open access article distributed under the Creative Commons Attribution License, which permits unrestricted use, distribution, and reproduction in any medium, provided the original work is properly cited.

The Latin Society for Vascular Research LIAC (Latinorum Investigatorum de Arteriis Colloquium) is a working group devoted to

(i) improving the quality of basic and applied research in all areas of vascular biology,

(ii) enhancing communications between chemists, biologists, engineers, and clinicians involved in these disciplines throughout the Latin world,

(iii) promoting joint or coordinated projects within the framework of European Union.

The 2013 annual conference of the Latin Society for Vascular Research, organized by the Dipartimento di Scienze Biomediche, Università degli Studi di Sassari, took place in Alghero (Sassari, Italy), http://www.liac2013.uniss.it/, and focused on several issues concerning cardiovascular pathophysiology and therapeutics.

As the scientific fields covered include structural biology, biophysics, biochemistry, genetics, molecular biology, cell and tissue biology, tissue engineering, biomaterials, pathologies, and therapeutics, the meeting represented an interesting platform for both young scientists and pure and applied research scientists and clinicians to share and discuss the latest results of their researches. Furthermore, as a significant number of students attended the meeting, it represented a quite effective way of disseminating science.

During the four-day meeting (September 18th-21st, 2013), several important topics related to vascular biology such as "Molecular and supramolecular structure," "Biomaterials and tissue engineering," "Cardiovascular cell biology," "Cardiovascular pathophysiology and modeling," and "Clinical approach" were covered.

Each session started with invited lectures of well-known researchers in the respective scientific field. The opening session "Science and philosophy," in memory of Professor Antonio Tamburro, consisted of an inaugural lecture, delivered by Professor Marco Milanese, titled "Archaeology and sciences. The biological archives of medieval and postmedieval Alghero." The sessions "Molecular and supramolecular structure" and "Cardiovascular cell biology" focused on the molecular processes involved in vascular pathophysiology. Several lectures dealt with extracellular matrix (ECM) remodeling that represents a crucial event in the onset of vascular diseases. In this context, ECM components, such as hyaluronan, tropoelastin, and elastin-derived peptides, seem to play a critical role.

The "Biomaterials and tissue engineering" session included reviews regarding some methods to develop xenogeneic tissues and 3D biomatrix constructs both highly 
biocompatible for clinical purposes. The "Cardiovascular pathophysiology and modeling" session provided an overview of the several tools proposed to model congenital heart diseases, evaluating the pros and cons associated with each methodology.

In the last session, "Clinical approach," some translational researches on carotid and coronary atherosclerosis, type I and II diabetes, stroke, and limb ischemia were discussed.

Overall, the event was a great success providing an attractive opportunity for scientists from Latin World to share their own outstanding researches with each other and with a number of students fascinated by cardiovascular pathophysiology.

\title{
Acknowledgments
}

The meeting was held under the auspices of Università degli Studi di Sassari, Dipartimento di Scienze Biomediche, and International $\mathrm{PhD}$ School in Biomolecular and Biotechnological Sciences, and was supported financially by Università degli Studi di Sassari, Fondazione Banco di Sardegna, and ERSU Sassari (Ente Regionale per il diritto allo Studio Universitario).

\author{
Marilena Formato \\ Vincenzo La Carrubba \\ Antonio J. Lepedda \\ Philippe Charpiot \\ José Carlos Rodriguez-Cabello
}




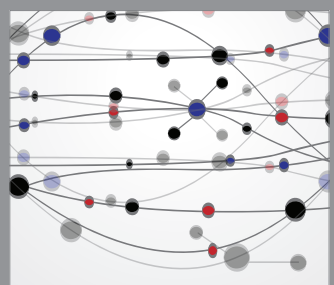

The Scientific World Journal
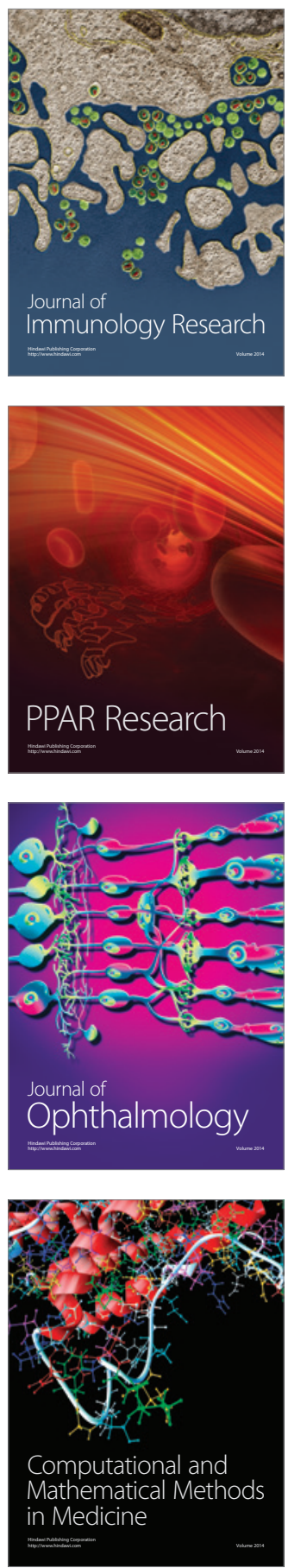

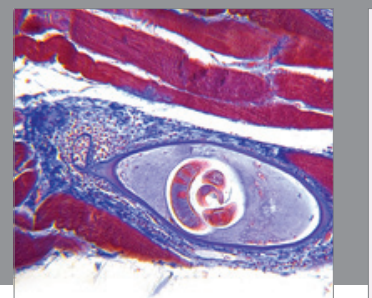

Gastroenterology

Research and Practice
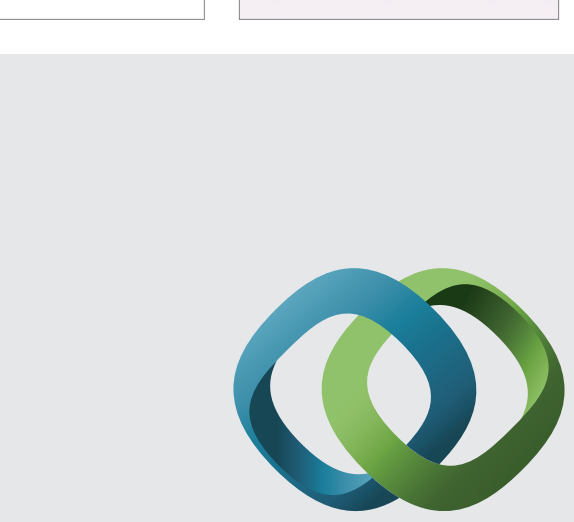

\section{Hindawi}

Submit your manuscripts at

http://www.hindawi.com
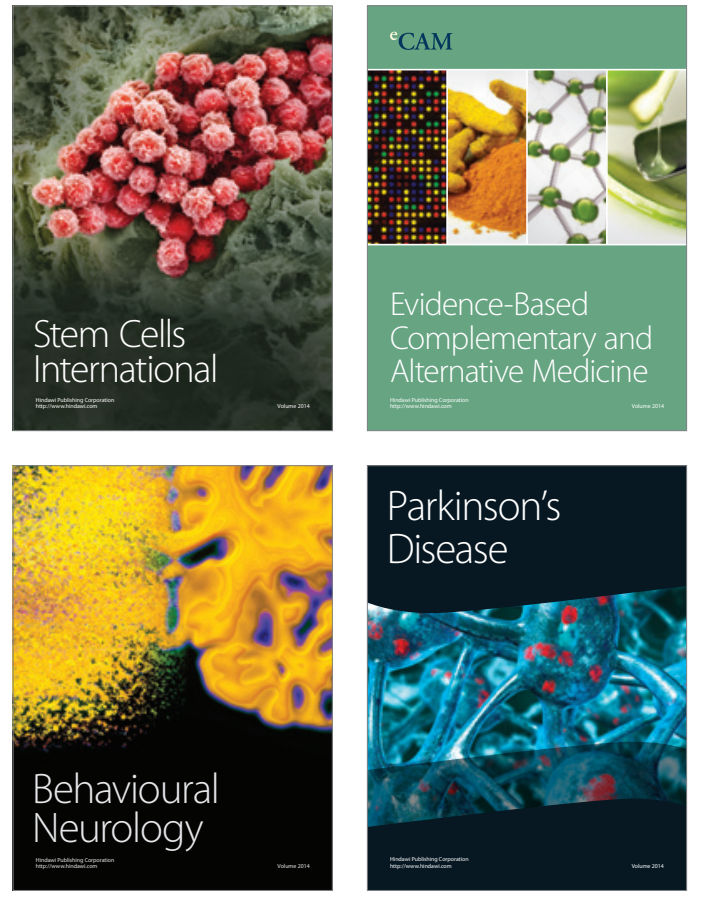
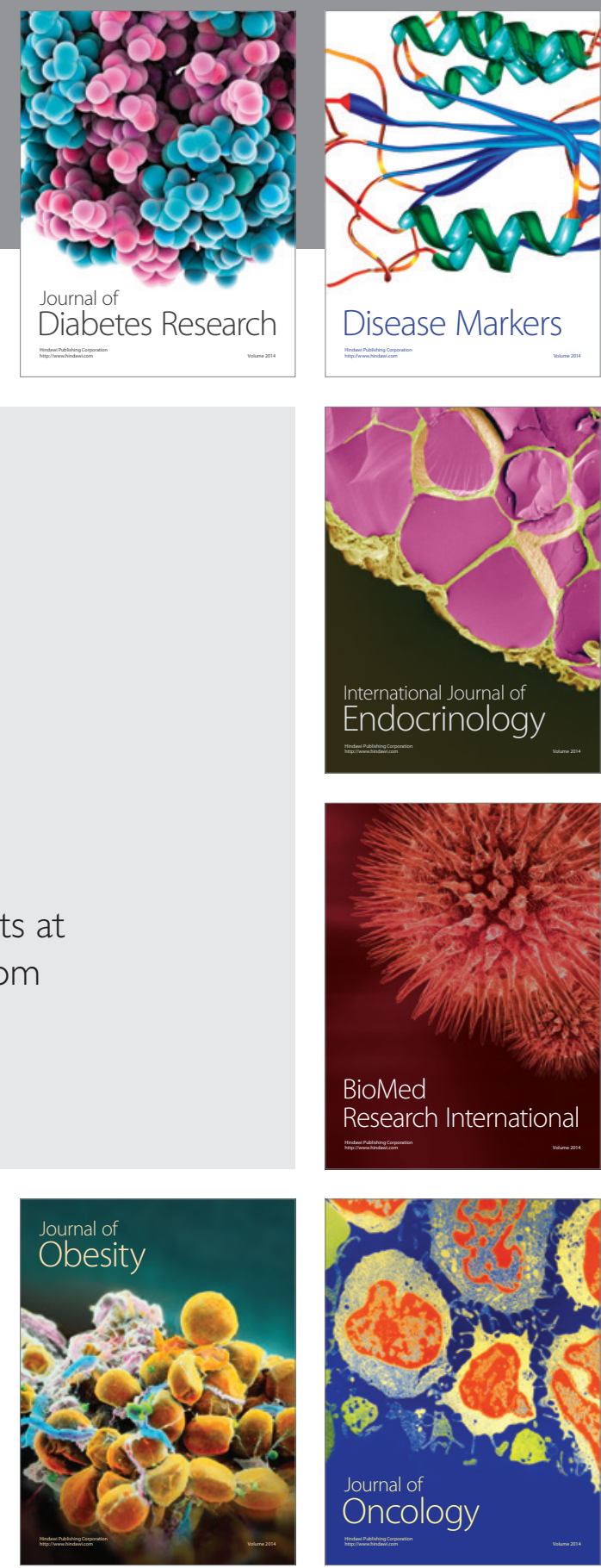

Disease Markers
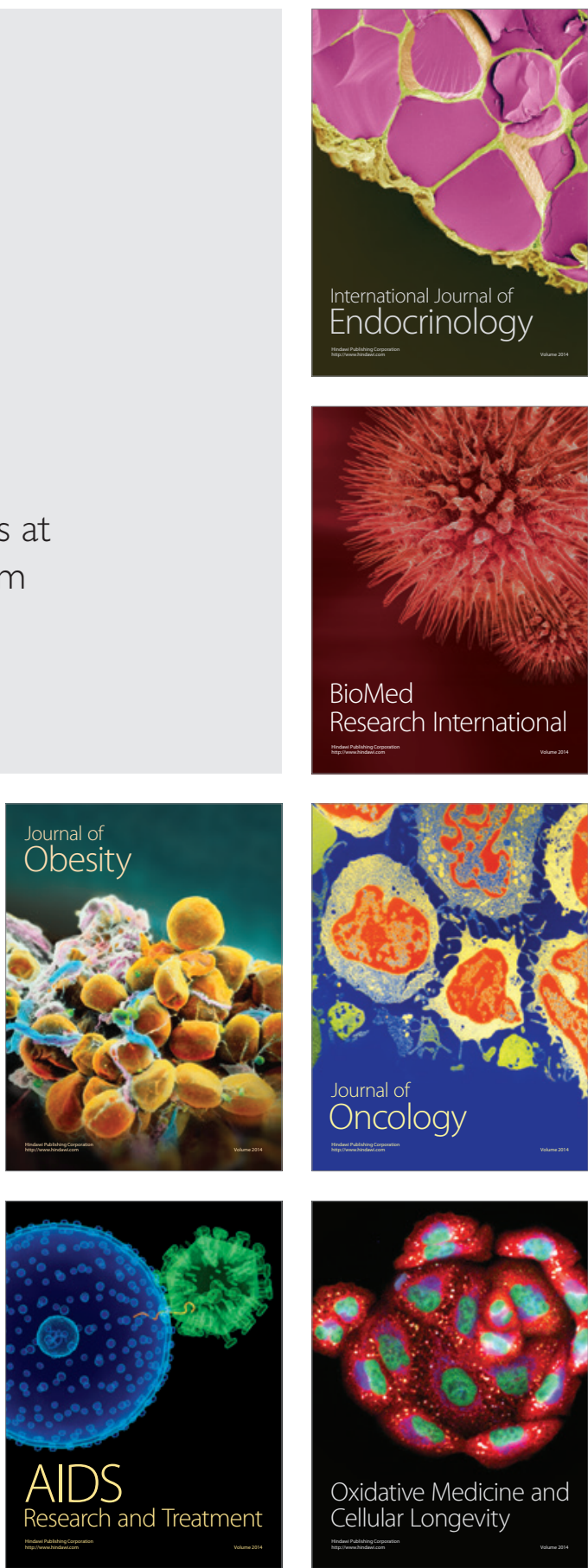